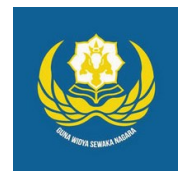

Jurnal Analogi Hukum

Journal Homepage: https://ejournal.warmadewa.ac.id/index.php/analogihukum

\title{
Pelaksanaan Tanggung Jawab Sosial Perusahaan Pada BPR di Kabupaten Badung
}

\author{
I Putu Bayu Pramana*, I Made Arjaya dan Desak Gede Dwi Arini \\ Universitas Warmadewa, Denpasar-Bali, Indonesia \\ *pramanabayu@gmail.com
}

How To Cite:

Pramana, I, P, B., Arjaya, I, M., Arini, D, G, D. (2020). Pelaksanaan Tanggung Jawab Sosial Perusahaan Pada BPR di Kabupaten Badung. Jurnal Analogi Hukum. 2 (3). 304-309. Doi: https://doi.org/10.22225/ah.2.3.2503.304-309

\begin{abstract}
The company is a place where it aims to improve the lives of the people. In its development in the economic and business sectors the role of the company in terms of improving the country's economy is a responsibility of each company, in this case it is called corporate social responsibility (CSR). In this study, focusing on the implementation of CSR in BPR in Badung Regency, where the BPR is expected to be able to prosper the surrounding community and carry out the mandate of the PERDA of Badung Regency No. 6 of 2013 concerning Corporate Social Responsibility. From this background two problems can be formulated, namely: 1). What is the regulation of social responsibility (CSR) in the annual BPR activity plan in Badung Regency? 2). What is the implementation of the annual activity plan that regulates social responsibility (CSR) in rural banks in Badung Regency? the method used is empirical research method, which is research directly in the field. The results of this are social responsibility is the company's commitment to improving the economy of the community that benefits the company and the general public, where the regulation of corporate social responsibility in BPR in Badung Regency is Law No. 40 of 2007 concerning Limited Liability Companies, PP No. 47 of 2012, and Badung District Regulation No. 6 of 2013. In its implementation social responsibility (CSR) in BPR in Badung Regency has been running well as in terms of education providing scholarships to outstanding students and the introduction of banking products to the local community.
\end{abstract}

Keywords: Social Responsibility; BPR; Companies

\begin{abstract}
Abstrak-Perusahaan merupakan suatu wadah yang bertujuan besar untuk meningkatkan taraf kehidupan masyarakat. Dalam pengembangannya pada sektor ekonomi dan bisnis peran perusahaan dalam hal meningkatkan perekonomian Negara merupakan suatu tanggung jawab dari setiap perusahaan, dalam hal ini disebut tanggung jawab sosial perusahaan (CSR). Dalam penelitian ini memfokuskan penerapan CSR pada BPR di Kabupaten Badung yang mana BPR ini diharapkan mampu mensejahterakan masyarakat sekitar dan menjalankan amanat PERDA Kabupaten Badung No 6 Tahun 2013 tentang Tanggung Jawab Sosial Perusahaan. Dari latar belakang tersebut dapat dirumuskan dua permasalahan yaitu : 1). Bagaimana pengaturan tangung jawab sosial (CSR) pada rencana kegiatan tahunan BPR di Kabupaten Badung? 2). Bagaimana pelaksanaan rencana kegiatan tahunan yang mengatur tanggung jawab sosial (CSR) pada BPR di Kabupaten Badung ? metode yang digunakan yaitu metode penelitian empiris, yang mana penelitian secara langsung kelapangan. Hasil dari ini yaitu tanggung jawab sosial merupakan komitmen perusahaan dalam meningkatkan perekonomian masyarakat yang bermanfaat bagi perusahaan dan masyarakat umum yang dimana pengaturan tanggung jawab sosial perusahaan pada BPR di Kabupaten Badung yaitu UU No 40 Tahun 2007 Tentang Perseroan Terbatas, PP No 47 Tahun 2012, dan Peraturan Daerah Kabupaten Badung No 6 Tahun 2013. Dalam pelaksanaannya tanggung jawab sosial (CSR) pada BPR di Kabupaten Badung sudah berjalan baik seperti dalam hal pendidikan pemberian beasiswa kepada siswa/siswi yang berprestasi dan pengenalan produk perbankan kepada masyarakat setempat.
\end{abstract}

Kata Kunci: Tanggung Jawab Sosial ; BPR ; Perusahaan

Jurnal Analogi Hukum, Volume 2, Nomor 3, 2020. CC-BY-SA 4.o License 


\section{Pendahuluaan}

Tanggung jawab sosial perusahaan adalah terjemahan dari corporate sosial responsibility yang selanjutnya disingkat sebagai (CSR) (Susanto, 2007). Tanggung jawab sosial perusahaan seperti apa yang telah direncanakan lembaga, bersitfat aktif dan partisipasi dalam masyarakat untuk mempertahankan serta meningkatkan lingkungan untuk kepentingan antara lembaga dan masyarakat (Suparman, 2013). Dalam perkembangannya, istilah corporate social responsibility ( CSR ) atau tanggung jawab sosial kini sudah semakin populer dikalangan masyarakat dan perusahaan dengan semakin meningkatnya praktek tanggung jawab sosial perusahaan, dan diskusi diskusi global, regional dan nasional tentang CSR (Gumilar, A, \& Melianny, 2017). Perusahaan mempunyai tanggung jawab yang sangat besar akan kemajuan perekonomian suatu Negara yang pengembangannya di sektor ekonomi dan bisnis. Dalam persaingan yang dilakukan oleh masing-masing perusahaan di dasari atas keuntungan individu perusahaan, namun perusahaan tidak hanya berorientasi terhadap diri mereka sendiri saja perusahaan juga memiliki tanggung jawab terhadap kesejahtraan masyarakat disekitarnya (Velasquez, 2002).

Perusahaan yang diwajibkan melaksanakan tanggung jawab sosial perusahaan yaitu perusahaan yang berbentuk Perseroan terbatas yang dalam penelitian ini adalah penyedia jasa perbankan dalam bentuk Perseroan Terbatas tak terkecuali BPR sesuai dengan pasal 74 UndangUndang Nomor 40 Tahun 2007 Tentang Perseroan Terbatas.

Kabupaten Badung merupakan satu satunya kabupaten di Bali yang telah mengeluarkan Peraturan yang mengkhusus terkait pelaksanaan tanggung jawab sosial yakni dalam bentuk PERDA Kabupaten Badung No. 6 Tahun 2013 Tentang Tanggung Jawab Sosial Perusahaan. Berdasarkan hal tersebut penulis tertarik melakukan penelitian secara ilmiah tentang pelaksanaan tanggung jawab soaial perusahaan yakni BPR di Kabupaten Badung.

Berdasarkan uraian latar belakang di atas maka didapat dua rumusan permasalahan sebagai berikut: 1. Bagaimana pengaturan tanggung jawab sosial perusahaan (CSR) pada rencana kegiatan tahunan BPR di Kabupaten Badung? 2. Bagaimana pelaksanaan rencana kegiatan tahunan yang mengatur tanggung jawab sosial perusahaan (CSR) pada BPR di Kabupaten Badung?
Tanggung jawab perusahaan adalah sebuah bentuk tanggung jawab perusahaan atau organisasi yang memiliki berbagai bentuk tanggung jawab terhadap seluruh pemangku kepentingan, diantaranya konsumen, karyawan pemegang saham komunitas dan lingkungan dalam segala aspek oprasional perusahaan yang juga mencakup aspek ekonomi, sosial dan lingkungan maka berkaitan dalam mendukung pembangunan yang berkelanjutan (Azheri, 2012).

\section{Metode}

Metode penelitian yang digunakan dalam memecahkan permasalahan tersebut diatas yaitu tipe penelitian dan pendekatan masalah yang digunakan adalan penelitian hukum empiris yang mana penelitian yang dilakukan secara langsung ke lapangan, sumber data yang digunakan yaitu sumber data primer yang mana data bersumber dari penelitian secara langsung ke lapangan, kedua sumber data sekunder yaitu data yang bersumber dari menelaah literaturliteratur yang berkaitan dengan permasalahan diatas (Soekanto, 2007).

Teknik pengumpulan data yang dipergunakan adalah teknik pengumpulan data kepustakaan yang mana dalam teknik ini menghasilkan sumber data sekunder dan teknik penelitian lapangan yang mana menghasilkan sumber data primer.

Penelitian ini dilakukan di tiga lokasi dan berbeda kecamatan. Diantara 6 kecamatan di Kabupaten Badung dipilih 3 kecamatan yakni, Kecamatan Abiansemal di PT. BPR Sangeh yang beramat di. Jln Raya Sangeh. Lokasi kedua berada di kecamatan Mengwi di PT. BPR Parasari yang beralamat di Jln. Raya Lukluk. Lokasi ketiga berada di Kuta di PT. BPR Sinar Kuta Mulia yang beralamat di Jln. Raya Kuta. Setelah data terkumpul maka data tersebut diolah dan di Analisa secara deskritif yaitu menganalisa dari permasalahan yang timbul di lapangan.

\section{Hasil Penelitian dan Pembahasan}

\section{Pengaturan Tanggung Jawab Sosial Perusahaan (CSR) Pada Rencana Kegiatan Tahunan BPR Di Kabupaten Badung}

Tanggung jawab sosial perusahaan merupakan suatu komitmen perusahaan dalam rangka turut serta meningkatkan taraf perekonomian suatu Negara yang mana hal ini merupakan perwujudan dari Undang- Undang Dasar 1945 pasal 33 ayat 1 dan 4 yang menentukan bahwa perekonomian disusun 
sebagai usaha bersama berdasarkan atas asas kekeluargaan dan perekonomian nasional diselenggarakan berdasarkan atas demokrasi ekonomi dengan prinsip kebersamaan, efisiensi berkeadilan, berkelanjutan, berwawasan lingkungan kemandirian, serta kemajuan dan keseimbangan dan kesatuan perekonomian Nasional (Untung, 2007). Berdasarkan hasil Penelitian yang telah dilakukan maka pengaturan tentang pelaksanaan tanggung jawab sosial (CSR) pada BPR di Kabupaten Badung yaitu, Undang-Undang No 40 Tahun 2007 Tentang Perseroan Terbatas, peraturan pemerintah No. 47 Tahun 2012 tentang Tanggung Jawab Sosial dan khusus di Kabupaten Badung diatur dalam PERDA Kabupaten Badung No. 6 Tahun 2013 Tentang Tanggung Jawab Sosial.

\section{Pelaksanaan Rencana Kegiatan Tahunan Yang Mengatur Tanggung Jawab Sosial Perusahaan (CSR) Pada BPR Di Kabupaten Badung}

Yang mana penelitian ini dilakukan di tiga BPR di Kabupaten Badung yakni di BPR Sangeh, BPR Parasari, BPR Sinar Kuta Mulia, yang mana pelaksanaannya yaitu:

\section{BPR Sangeh}

Sesuai dengan visi dan misi dari BPR SANGEH dimana bertujuan untuk meningkatkan taraf kehidupan masyarakat sekitar dengan menerapkan CSR yang dimana bentuk penerapan CSR yang dilakukan oleh BPR SANGEH yaitu:

Dalam bentuk pendidikan menurut wawancara pada tanggal 9 Januari 2019 dengan Drs. Ida Bagus Kerta selaku Direktur dari BPR SANGEH beliau memaparkan bahwa bentuk CSR dalam hal pendidikan BPR SANGEH memberikan edukasi perkenalan produk perbankan dengan pemberian dana prestasi kepada 36 siswa berlokasi di Sekolah Dasar No 1 Sangeh dan Sekolah Dasar No 3 Sangeh yang dimana bentuk CSR ini diberikan rutin setiap tahunnya dengan anggaran biaya sebesar Rp. 4,500.000,00 dengan rincian:

Juara 1 kelas masing-masing mendapatkan tanda penghargaan berupa uang sebesar Rp. 150.000,00

Juara 2 kelas masing-masing mendapatkan tanda penghargaan berupa uang sebesar Rp. 125.000,00

Juara 3 kelas masing-masing mendapatkan tanda penghargaan berupa uang sebesar Rp. 100.000,00

Selanjutnya menurut wawancara dengan Drs. Ida Bagus Kerta bentuk penerapan CSR yang dilakukan oleh BPR SANGEH yaitu dalam bentuk bantuan sosial, dimana:

Pada tanggal 14 September 2016 menerapkan program pemberdayaan masyarakat dimana dengan memberikan batuan dana sebesar Rp. 7.500,000,00 dengan rincian :

Memberikan bantuan kepada PKK di Banjar Batur Sari sebesar Rp. 1.500.000,00

Memberikan bantuan kepada PKK di Banjar Brahmana sebesar Rp. 1.500.00,00

Memberikan bantuan kepada PKK di Banjar Sibang sebesar Rp. 1.500.000,00

Memberikan bantuan kepada PKK di Banjar Pemigian sebesar Rp. 1.500.000,00

Memberikan bantuan kepada PKK di Banjar Muluk Babi sebesar Rp. 1.500.000,00

Pada tanggal 20 November 2017 menerapkan program pembinaaan masyarakat dengan memperkenalkan produk perbankan kepada masyarakat yang melibatkan 1.500 orang, dimana acara tersebut berlangsung di Objek Wisata Sangeh dengan anggaran biaya $\mathrm{Rp}$. 105.000.000,00 yang dimana dana tersebut dipergunakan untuk pemberian hadiahhadiah dan biaya berlangsungnya acara tersebut.

Pada tanggal 17 Agustus 2018 menerapkan program bakti sosial yang berlokasi di Taman Tirta Mumbul dan sekitarnya dan melibatkan 600 orang untuk mengumpulkan sampah plastik dengan anggaran biaya sebesar Rp. 65.000.000,00. Dana tersebut dipergunakan untuk pemberian door price berupa sepeda motor dan alat-alat elektronik, dana tersebut juga dipergunakan untuk pembiayaan berlangsungnya acara tersebut. 


\section{BPR Parasari}

Bentuk penerapan CSR yang dilakukan oleh BPR PARASARI LUKLUK diterangkan pada wawancara tanggal 11 Januari 2019 dengan I Gusti Ngurah Anom Amijaya,SE. selaku Dewan Komisaris, beliau menegaskan bahwa:

Pada Tanggal 17 Agustus 2016 bentuk penerapan CSR yang dilakukan BPR PARASARI LUKLUK yaitu berupa bantuan sosial dengan menerapkan program CSR yang meliputi pembinaan masyarakat dengan memperkenalkan produk perbankan yang dimiliki oleh BPR PARASARI LUKLUK dengan total biaya sebesar RP. 120.000.000,00 yang berlokasi di Wantilan Desa Adat Lukluk dengan susunan acara, Jalan Santai dengan diikuti oleh 5 banjar di wilayah Desa Adat Lukluk dilanjutkan dengan lomba-lomba dan pengundian door price dengan hadiah utama sepeda motor dan alat-alat elektronik

Pada tanggal 28 Oktober 2016 untuk memperingati Hari Sumpah Pemuda BPR PARASARI LUKLUK bentuk penerapan CSR berupa bantuan sosial dimana BPR PARASARI LUKLUK memberikan bantuan dana kepada karang taruna Desa Adat Lukluk yang mana dipergunakan untuk mengadakan turnamen volly dengan anggran biaya $\mathrm{Rp}$. 10.000.000,00 yang berlokasi lapangan volley Banjar Delod Perempatan.

Pada tanggal 09 Juni 2017 bertepatan dengan pergantian semester bentuk penerapan CSR yang digunakan adalah bentuk penerapan pendidikan dengan memberikan edukasi dan pengenalan produk perbankan kepada siswa di wilayah Desa Adat Lukluk dengan anggran biaya Rp. 8.400.000,00 dengan rincian:

Sekolah Dasar No 1 Lukluk mendapatkan tanda penghargaan bagi siswa yang mendapatkan juara kelas berupa uang dengan jumlah total yang diberikan Rp. 2.100.000,00

Sekolah Dasar No 2 Lukluk mendapatkan tanda penghargaan bagi siswa yang mendapatkan juara kelas berupa uang dengan jumlah total yang diberikan Rp. 2.100.000,00

Sekolah Dasar No 3 Lukluk mendapatkan tanda penghargaan bagi siswa yang mendapatkan juara kelas berupa uang dengan jumlah total yang diberikan Rp. 2.100.000,00

Sekolah Dasar No 4 Lukluk mendapatkan tanda penghargaan bagi siswa yang mendapatkan juara kelas berupa uang dengan jumlah total yang diberikan Rp. 2.100.000,00.
Pada tanggal 05 Februari 2018 bertepatan dengan HUT BPR PARASARI LUKLUK bentuk CSR yang dilakukan oleh BPR PARASARI LUKLUK adalah dalam bentuk ekonomi yaitu dengan program pengembangan usaha dan memberdayakan masyarakat sekitar, dengan melakukan pengenalan produk perbankan yaitu dalam jenis kredit UKM. Acara tersebut berlangsung di pasar tradisional Desa Pekraman Sempidi. Dimana para staf di BPR PARASARI LUKLUK melakukan pendekatan terhadap pedagang-pedagang di pasar Desa Pekraman Sempidi dengan menjelaskan salah satu jenis produk perbankan yaitu kredit usaha kecil/ UKM.

\section{BPR Tapa}

Menurut wawancara pada tanggal 10 Februari 2019 dengan Wayan Mustika, S.E selaku Kepala Pengawas Internal di BPR Tapa Pelaksnaan CSR di BPR Tapa dilaksanakan 2 kali selama 1 tahun dilakukan bersama sama dengan Perbarindo Bandung masyarakat Pasar dan Sekolah dengan penyerahan sovenir dengan pengenalan produk perbankan Tirtayatra, donor darah dengan dalam pelaksanaan CSR rincian acara:

Pada tahun 2017 kegiatan Bulanan Keuangan Pada Pelaksanaan kegiatan edukasi yang dilakukan PERBARINDO DPK BADUNG yang berkaitan dengan permasalahan pendidikan, maka PERBARINDO BPK BADUNG melaksanakan edukasi dan literasi keuangan kepada siswa-siswa dengan harapan agar pengetahuan siswa tekait edukasi dan literasi keuangan dapat ditingkatkan sesuai dengan harapan otoritas jasa keuangan (OJK). Pelaksanaan ini dilaksanakan di SMA NEGERI 1 KUTA UTARA pada tanggal 13 Oktober 2017 dengan peserta berjumlah kurang lebih 150 orang yang berasal dari pelajar SMA NEGERI 1 KUTA UTARA dengan rincian acara sebagai berikut:

Pembukaan

Sambutan oleh Ketua PARINDO BPK BADUNG

Sambutan oleh Kepala SMA NEGERI 1 KUTA UTARA

\section{Penyerahan cindera mata}

Edukasi literasi keuangan dibawakan oleh I Ketut Wardana, SE.,M.Si dan I Gusti Ngurah Gede Muliawan, SE.,MM dengan memperkenalkan dan menanyakan produk dan pengetahuan terkait dengan literasi keuangan. 
Dalam pelaksanaan literasi dan edukasi panitia memberikan sovenir kepada peserta edukasi.

Pada Tanggal 23 Mei 2017 berkaitan dengan permasalahan dimana rendahnya pengetahuan dan pemahaman masyarakat Indonesia terhadap lembaga keuangan produk dan layanan jasa keuangan masih relative rendah dan tidak merata pada setiap sektor industry jasa keuangan maka PERBARINDO BPK BADUNG dengan BPR TAPA melaksanakan kegiatan edukasi dan literasi keuangan kepada masyarakat seDesa Sibang Kaja bekerja sama dengan Perbekel Desa Sibang Kaja, dengan harapan agar pengetahuan masyarakat terkait edukasi dan literasi keuangan dapat ditingkatkan ssuai dengan Otoritas Jasa Keuangan. Pelaksanaan CSR dalam kegiatan edukasi dan literasi keuangan dilaksanakan di Desa Sibang Kaja dengan peserta ibu-ibu PKK dari 7 banjar yang ada pada wilayah Perbekel Sibang Kajadengan jumlah peserta kurang lebih 150 sampai 200 orang peserta dimana acara tersebut dibawakan oleh group lawak bali bondres Sengeng dan Artis Bali dipandu oleh panitia dalam memperkenalkan BPR produk dan pengetahuan terkait dengan literasi keuangan dalam pelaksanaan edukasi dan literasi panitia memberikan sovenir bagi peserta edukasi dan literasi keuangan bagi peserta yang bisa menjawab pertanyaan terkait dengan literasi keuangan.

Pada Tahun 2018 berkaitan dengan permaslahan pelaku jasa keuangan (PUJK) terutama BPR belum sepenuhnya dikenal masyarakat secara umum. Baik itu dari sisi kelembagaannya produk maupun layanan yang disediakan PUJK itu sendiri rendahnya kepedulian dari dirinya sendiri terhadap PUJK, rendahnya pemanfaatan lembaga, produk dan layanan jasa keuangan yang disediakan PUJK oleh masyarakat itu sendiri. Untuk meningkatkan literasi keuangan tertuang dalam POJK No. 01/SE.OJK.7/2014 maka PERINDO BPK BADUNG melaksanakan kegiatan literasi dan edukasi keuangan kepada siswa Pariwisata Mengwitani, Badung, Bali dengan harapan pengetahuan siswa terkai dengan edukasi dan literasi keuangan dapat ditingkat sesuai dengan Otoritas Jasa Keuangan. Kegiatan ini dilaksanakan di SMK PARIWISATA MENGWITANI Pada Tanggal 20 Juli 2018 dengan peserta kurang lebih 100 orang dimana merupakan pelajar SMK MEGWITANI dengan kegiatan edukasi dan literasi keuangan yang dibawakan oleh I Gusti Ngurah Budiawan, SE., MM dengan memperkenalkan dan menanyakan produk dan pengetahuan terkait dengan literasi keuangan. Dalam pelaksanaan edukasi dan literasi panitia memberikan souvenir bagi peserta edukasi dan literasi keuangan bagi peserta yang bisa menjawab pertanyaan terkait dengan literasi keuangan.

\section{Simpulan}

Pengaturan Tanggung Jawab Sosial Perusahaan (CSR) pada rencana kegiatan tahunan BPR di Kabupaten Badung yaitu, Tanggung Jawab Sosial Perusahaan (CSR) merupakan suatu komitmen perusahaan untuk ikut serta/ berperan dalam meningkatkan perekonomian masyarakat dan bertujuan untuk meningkatkan taraf kehidupan masyarakat. Serta bermanfaat bagi komunitas setempat, masyarakat dan perseroan itu sendiri, yang dimana penerapan Tanggung Jawab Sosial Perusahaan (CSR) diatur dalam Pasal 74 UU No 40 Tahun 2007 dan PP No 47 Tahun 2012. Khusus untuk Kabupaten Badung, Penerapan Tanggung Jawab Sosial Perusahaan (CSR) pada BPR di Kabupaten Badung diatur dalam Peraturan Daerah Kabupaten Badung Nomor 6 Tahun 2013 Tentang Tanggung Jawab Sosial.

Pelaksanaan Rencana Kegiatan Tahunan yang mengatur tentang Tanggung Jawab Sosial Perusahaan (CSR) pada BPR di Kabupaten Badung dalam pelaksanaannya, prosedur pelaksanaan CSR di Kabupaten Badung terdapat 2 yaitu: prosedur pengajuan proposal kegiatan dan prosedur pengendalian anggaran dan pelaksanaan Tanggung Jawab Sosial Perusahaan pada setiap Tahunnya di Kabupaten Badung sudah dilaksanakan dengan baik, dimana Pelaksanaannya masuk ke dalam sektor pendidikan yaitu pemberian beasiswa kepada siswa yang berprestasi dan pemberian bantuan ke banjar-banjar sekitar, serta memperkenalkan produk perbankan yang dimiliki oleh masingmasing BPR..

\section{Daftar Pustaka}

Azheri, B. (2012). Corporate Social Responsibility. Jakarta: Raja Grafindo Persada.

Gumilar, S., A, H. R., \& Melianny, L. (2017). Tanggung Jawab Sosial Perusahaan ( Csr ) Studi Efektifitas Program Pt. Pertamina Sehati (Sehat Ibu Dan Anak Tercinta). Jurnal Penelitian \& PKM, 4 (2). Retrieved from http:// jurnal.unpad.ac.id/prosiding/article/ download/14291/6906 
Soekanto, S. (2007). Pengantar Penelitian Hukum. Jakarta: Universitas Indonesia.

Suparman. (2013). Coorporate Social Responsibility: Bentuk tanggunga jawab social dan Kepedulian Perusahaan dengan Masyarakat. Jurnal Interaksi, 2(2). Retrieved from http://jurnal.unpad.ac.id/ p r o s i d i n g / a r t i c l e / download/14291/6906

Susanto, A. B. (2007). Corporate Social Responsibility. Anstrategic Management Approach. Jakarta: The Jakarta Consulting Group.

Untung, H. B. (2007). Coorporate Social Responsbility. Jakarta: Sinar Grafika.

Velasquez, M. G. (2002). Etika Bisnis: Konsep dan kasus. Yogyakarta. 